\title{
Assessment of Toxicity Issues of Bis-Coumarine Derivates and their Lanthanoid Complexes by Statistical Data Analysis
}

\author{
V Kircheva' ${ }^{1}$ D Josifov ${ }^{2}$, M Milanova*1, I Pancheva ${ }^{1}$, J Zaharieva ${ }^{1}$, M Nedyalkova ${ }^{1}$, S Konstantinov ${ }^{2}$, V Simeonov ${ }^{1}$ and I $^{2}$ \\ Manolov ${ }^{3}$ \\ ${ }^{1}$ University of Sofia "St. Kliment Ohridski”, Department of Inorganic Chemistry, Bulgaria \\ ${ }^{2}$ Medical University of Sofia, Department of Pharmacology, Bulgaria \\ ${ }^{3}$ Medical University of Sofia, Department of Organic Chemistry, Bulgaria
}

Received: 制: September 24, 2018; Published: 制: October 09, 2018

*Corresponding author: M Milanova, University of Sofia "St. Kliment Ohridski", Faculty of Chemistry, Department of Inorganic Chemistry, 1, J. Bourchier Blvd, 1164 Sofia, Bulgaria

\begin{abstract}
Complexes of some lanthanoids with several biscoumarin compounds such as 3,3'- benzylidenebis(4-hydroxy-2H-chromen-2-one), 3,3'-[(2-methoxyphenyl) methylene)]bis(4-hydroxy-2H-chromen-2-one), 3'-[(4-methoxyphenyl)methylene)]bis(4-hydroxy-2H-chromen-2-one) and 3,3'-[(4-chlorophenyl)methylene)]bis(4-hydroxy-2H-chromen-2-one) were synthesized. The assessment of toxicity both ligands and the complexes formed was made through testing their antibacterial properties and cytotoxicity as two independent activities were studied. Three Grampositive microorganisms were used, B. Mycoides, B. Subtilis and S. Lutea, applying the double layer agar hole diffusion method. The tested compounds were active against Gram-positive bacteria, but no activity was measured against Gram-negative bacteria. Cytotoxicity evaluation was made against cell lines such as K-562, BV-173, and SKW-3. The cluster analysis as a technique of the statistical data analysis was applied to the results obtained.
\end{abstract}

\section{Introduction}

\section{Biological Activity of Coumarin Derivates and their Lanthanoid Complexes}

Coumarin (2H-1-benzopyran-2-one) and its derivates are large class of chemical compounds, most of them naturally occurring and can be found in plants [1], fungi and bacteria [2,3] or can be synthesized with a modification of the coumarin ring [4-6]. Due to the different types of substitution of the parent ring, coumarins are extremely variable in structure resulting in variety of their properties. Both natural and synthetic coumarins are reported to have properties such as antioxidant $[7,8]$, antifungal $[9,10]$, antitumor [11-13], anti-HIV [14,15], anticoagulant [16,17], antibacterial [18-20], etc. A suggestion has been made that the antibacterial activity depends on the position of substituents and the 3,3'-(4-hydroxybenzylidene)-bis-4-hydroxycoumarin skeleton is essential for the activity [18]. Besides the coumarins, their complexes with different metal ions have been found to possess antimicrobial activity i.e. the implementing of a metal ion in the structure of the coumarin can lead to enhancing its biological activity [21-23]. Complexes of lanthanoids with various coumarin compounds have been synthesized and screened for their biological activity [24-29].

\section{Testing Bacterial Activity}

In the microbiology several methods can be used for testing bacterial susceptibility according to the conditions. The selection of a method is based on many factors among them automation, cost, reproducibility, accuracy and individual preference. Bacterial susceptibility can be checked using disk diffusion method, broth macrodilution, broth microdilution or agar dilution method [20,3033]. Disk diffusion refers to the diffusion of an antimicrobial agent of a specified concentration from disks, tablets or strips, into the solid culture medium that has been seeded with the selected inoculum isolated in a pure culture. It is based on the determination of an inhibition zone proportional to the bacterial susceptibility to the antimicrobial present in the disk. The results depend on the concentration of the tested compound and its diffusibility. Disk diffusion is straightforward to perform, reproducible, and does not require expensive equipment. Agar dilution involves the incorporation of varying concentrations of antimicrobial agent into an agar medium, usually using serial twofold dilutions, followed by the application of a defined bacterial inoculum to the agar surface of the plate. It determines the lowest concentration of the assayed antimicrobial that inhibits the visible growth of the bacterium being 
tested, MIC, minimal inhibitory concentration, usually expressed in $\mu \mathrm{g} / \mathrm{ml}$ or $\mathrm{mg} / \mathrm{L}$. These results are often considered as the most reliable for the determination of MIC for the test bacterium/ antimicrobial combination [33].

\section{Testing Cytotoxicity}

The MTT assay has been used to determine the metabolic activity of cell lines in the presence of different substances [27-29]. This is a colorimetric assay based on the cleavage of the tetrazolium ring of MTT (3-(4,5-dimethylthiasol-2-yl)-2,5-diphenyl tetrazolium bromide) by dehydrogenases in active mitochondria of living cells as an estimate of viable cell number [34]. The MTT data usually are presented as percentage of the untreated control (set as 100\%) and fitted to sigmoidal concentration-response curves. Thus, the corresponding IC50 values could be calculated using non-linear regression analysis (GraphPadPrizm program).

\section{The Contribution of the Work Presented}

In the work presented four derivates of 4-hydroxycoumarin were used, all synthesized via Knoevenagel condensation [32], namely 3,3'-[phenylmethylene]bis-(4-hydroxy-2H-1-benzopyran2-one), L1; 3,3'-[(2-methoxyphenyl)methylene]bis-(4-hydroxy-2H1-benzopyran-2-one), L2; 3,3'-[(4-methoxyphenyl)methylene]bis(4-hydroxy-2H-1-benzopyran-2-one), L3; and 3,3'-[(4-chlorphenyl) methylene] bis-(4-hydroxy-2H-1-benzopyran-2-one), L15. The complexes prepared with lanthanoids Ln (III), denoted as NdL1, NdL2, NdL3 and LnL15 (Ln = Nd, Pr, Ho, Eu, Tb, Er, Yb) were characterized (characterization not included) and biologically screened. Both the ligands and complexes were tested for antibacterial activity against Gram-positive microorganisms, $B$. Mycoides, B. Subtilis and S. Lutea and Gram-negative bacteria E. Coli. The cytotoxicity against 3 cell lines was tested both for the ligand L15 and for the complexes LnL15 (Ln = Pr, Eu, Ho, Er, Yb). Our aim was to evaluate the influence of the implementing the lanthanoid ion in the ligand structure on the bioactivity. The statistical data analysis was applied for better understanding of the results.

\section{Experimental}

\section{Determination of the Cytotoxicity}

The compounds were dissolved in DMSO and their antiproliferative effect was evaluated against panel of malignant cell lines: K-562 (chronic myeloid leukemia in blast crisis), SKW3 (chronic lymphocytic leukemia) and BV-173 (chronic myeloid (B-cell precursor) leukemia), applying MTT assay as described in [34]. Statistical processing was applied exploiting Student's t-test with $\mathrm{P} \leq 0.05$ set as significance level, $\mathrm{n} \geq 3$ for each value.

\section{Determination of the Antibacterial Activity}

The double-layer agar hole diffusion method was applied. A nutrient agar (NA, containing $0.1 \% \mathrm{w} / \mathrm{v}$ meat extract, $1 \% \mathrm{w} / \mathrm{v}$ peptone, $0.5 \% \mathrm{w} / \mathrm{v} \mathrm{NaCl}, 1.5 \% \mathrm{w} / \mathrm{v}$ agar) medium was used. The compounds (ligands, complexes, and corresponding salts) were dissolved in DMSO to obtain concentration from $1 \mathrm{mg} / \mathrm{mL}$ to $0.5 \mu \mathrm{g} / \mathrm{mL}$. A preculture of the corresponding bacteria was grown in NA overnight at $23^{\circ} \mathrm{C}($ Gram $(+))$ and $37^{\circ} \mathrm{C}$ (Gram (-) bacteria). A suspension of each bacteria in sterile water was prepared. The turbidity of the inoculum $\left(\lambda=640 \mathrm{~nm}, \mathrm{~b}=1 \mathrm{~cm}\right.$, against $\left.\mathrm{H}_{2} \mathrm{O}\right)$ was adjusted with McFarland $4\left(0.4 \mathrm{~mL} 1 \% \mathrm{BaCl}_{2} \cdot 2 \mathrm{H}_{2} \mathrm{O}\right.$ and $9.6 \mathrm{~mL}$ $\left.1 \% \mathrm{H}_{2} \mathrm{SO}_{4}\right)$ standard. The suspension was dissolved in NA $(1.5 \%$ solution). The sterile agar $(10 \mathrm{~mL})$ and the inoculated medium $(10 \mathrm{~mL})$ were consecutively placed in Petri dishes. Each solution $(20 \mu \mathrm{L})$ was added into the holes $(\mathrm{d}=6 \mathrm{~mm})$ made after solidification of the agar. The diameter of inhibition zones was measured $24 \mathrm{~h}$ after the inoculation at $23^{\circ} \mathrm{C}$ for Gram (+) and at $37^{\circ} \mathrm{C}$ for Gram (-) strains. All the results were collected by three separate experiments. All the equipment and culture media were sterile. Because no activity was registered against the Gram-negative bacteria, data about E. Coli are not commented in the work presented.

\section{Results and Discussion}

\section{Cytotoxicity of the Ligand L15 and Some of the Lanthanoid Complexes}

The cytotoxicity tests performed showed that all the LnL15 ( $\mathrm{Ln}=\mathrm{Pr}, \mathrm{Eu}, \mathrm{Ho}, \mathrm{Er}, \mathrm{Yb}$ ) complexes have antiproliferative activity against the K-562, BV-173 and SKW-3 cell lines. The effectiveness of the compounds for inhibiting the cells to function is expressed as the half maximal inhibitory concentration $\left(\mathrm{IC}_{50}, \mu \mathrm{M}\right)$ and data are summarized further down in Table 1. It was observed that the BV-173 cell line is the most influenced by the complexes presented among the cell lines investigated; the behavior of the K-562 line is similar, while the SKW-3 cell line is the most resistant. The highest activity among all the complexes is shown by HoL15 against K-562, with an inhibition concentration, $\mathrm{IC}_{50}$, of $2.9(2.8-3.1) \mu \mathrm{M}$. The complexes HoL15 and YbL15 show a similar high activity against BV-173, respectively IC50 6.4(5.5-7.5) and 6.2(5.0-7.6) $\mu \mathrm{M}$. The complexes YbL15 and PrL15 show the lowest inhibitory effect against SKW-3. The activity of the complexes is different against the three examined cell lines, but no clear correlation is apparent between the activity and the properties of the lanthanoid (such as atomic number, for example). The ligand L15 shows a decreasing activity for deactivation of the cell lines SKW-3, BV-173, and K-562, with IC $_{50}$ values of 21(20-23), 30(26-38) and 72(57-89) $\mu \mathrm{M}$, respectively. Comparing the ligand with its complexes, it is obvious that the complexes are more active against the tested cell lines. The only exception is the lower activity of the complexes PrL15 and YL15 against SKW-3 in comparison to the higher activity of the ligand. The nature of the interaction of the compounds and their decomposition products with the cells, and their mode-of-action must be determined in order to obtain a complete pharmacological characterization of the novel compounds. Investigations should demonstrate the eventual viability of the compounds as pharmacological agents.

Table 1: Effectiveness of the compounds for inhibition of the functioning of the cells, expressed as half maximal inhibitory concentration $\left(\mathrm{IC}_{50}\right)$.

\begin{tabular}{|c|c|c|c|}
\hline Compound & \multicolumn{3}{|c|}{ IC $_{\mathbf{5 0}} \boldsymbol{\mu M}$} \\
\hline & BV-173 & K-562 & SKW-3 \\
\hline L15 & $30(26-38)$ & $72(57-89)$ & $21(20-23)$ \\
\hline Pr15 & $8.3(7.0-9.8)$ & $10.2(9.8-10.2)$ & $53.9(49.9-58.2)$ \\
\hline Eu15 & $11.1(9.2-13.4)$ & $8.7(7.1-10.8)$ & $9.2(6.5-13.1)$ \\
\hline
\end{tabular}




\begin{tabular}{|c|c|c|c|}
\hline Ho15 & $6.4(5.5-7.5)$ & $2.9(2.8-3.1)$ & $12.1(10.8-13.6)$ \\
\hline Er15 & $9.9(8.0-12.3)$ & $10.6(9.2-12.3)$ & $11.3(9.5-13.4)$ \\
\hline Yb15 & $6.2(5.0-7.6)$ & $8.9(8.3-9.5)$ & $53.2(50.2-56.3)$ \\
\hline
\end{tabular}

\section{Antibacterial Activity}

Three types of bacteria were tested for assessing the toxicity of four ligands (L1, L2, L3, L15) and six lanthanoid complexes (NdL1, NdL2, NdL3, NdL15, TbL15, EuL15). The results are presented further down in the Table 2. All the tested compounds showed activity against Gram (+) bacterial strains: B. Mycoides, B. Subtilis and $S$. Lutea. The size of the zones of inhibition was different for each compound towards each bacterial strain.

Table 2: Activity of complexes and ligands against B. Mycoides, B. Subtilis and S. Lutea.

\begin{tabular}{|c|c|c|c|}
\hline Bacteria & B. Mycoides & B. Subtilis & S. Lutea \\
\hline Compound & $\boldsymbol{\mu M}$ & $\boldsymbol{\mu M}$ & $\boldsymbol{\mu M}$ \\
\hline L1 & 600 & 1210 & 600 \\
\hline NdL1 & 285 & 285 & 285 \\
\hline L2 & 560 & 1130 & 560 \\
\hline NdL2 & 120 & 250 & 250 \\
\hline L3 & 560 & 560 & 1130 \\
\hline NdL3 & 760 & 760 & 760 \\
\hline L15 & 280 & 280 & 280 \\
\hline NdL15 & 74 & 148 & 74 \\
\hline TbL15 & 78 & 78 & 78 \\
\hline EuL15 & 78 & 78 & 78 \\
\hline
\end{tabular}

\section{Statistical Data Analysis}

The goal of the statistical analysis is to reveal hidden relationships between the objects (chemical compounds) or between the features which characterize them (toxicity parameters or bacteria type).

\section{Antibacterial Data Set}

To find groups of similarity between the objects hierarchical cluster analysis was applied (z-transform of the input data, squared Euclidean distance as similarity measure, Ward's method of linkage and Sneath's criterion for cluster significance). As seen from the raw data matrix the toxicity of the ligands towards all types of tested bacteria is significantly lower than that of the complex compounds. It was important to find if some patterns of specificity could be detected in the data set (keeping in mind its small dimension). In (Figure 1) the hierarchical dendrogram of clustering the chemical compounds is shown. Three major clusters are formed (significance level 1/3Dmax): K1: (L1, L2, L3, NdL3); K2: (NdL1, NdL2); K3: (L15, TbL15, NdL15, EuL15). The first cluster K1 is specified by the lowest toxicity level towards all three bacterial types (average values for each bacterium for the members in this cluster $620,915,762.5$, respectively). The second cluster $\mathrm{K} 2$ indicates intermediate toxicity level (average values 202.5, 267.5, 267.5, respectively) and K3 is the pattern with the highest toxicity level (averages of 127.5, 146, 127.5, respectively). A deeper understanding of the relationship between the structure and the activity of the compounds can contribute to the elucidating of the possible reason for the toxicity. It can contribute to the design of optimal agents, as well.

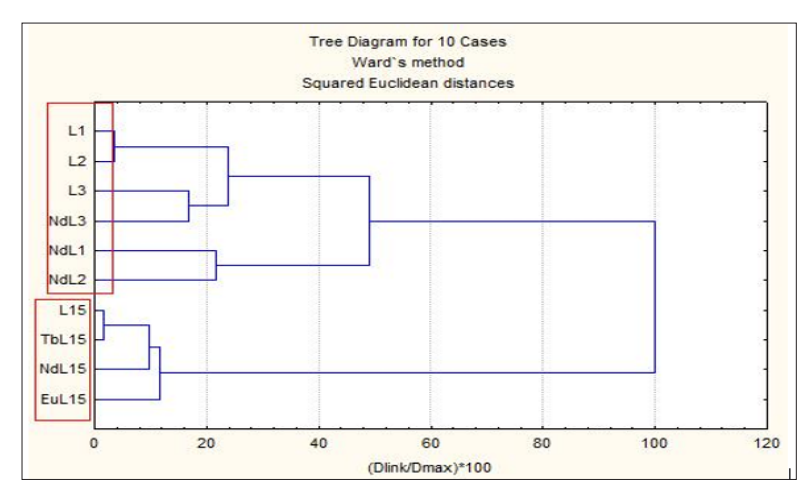

Figure 1: Dendrogram of clustering of the chemical compounds based on their antibacrterial activity.

To check the relationship between the bacterial types, correlation analysis of the input data was performed. The simple correlation matrix is shown in Table 3. It could be concluded that B. Mycoides reacts in a similar way as B. Subtilis and S. Lutea to the compounds toxicity but there is a difference in the response between B. Subtilis and S. Lutea. A possible reason could be the different morphology of the bacteria i.e. B. Subtilis are rod-shaped but $S$. Lutea are coccus (spherical) bacteria.

Table 3: Correlation matrix of the bacterial types.

\begin{tabular}{|c|c|c|c|}
\hline Bacteria & B.Mycoides & B.Subtilis & S.Lutea \\
\hline B.Mycoides & 1.00 & & \\
\hline B.Subtilis & 0.85 & 1.00 & \\
\hline S.Lutea & 0.86 & 0.65 & 1.00 \\
\hline
\end{tabular}

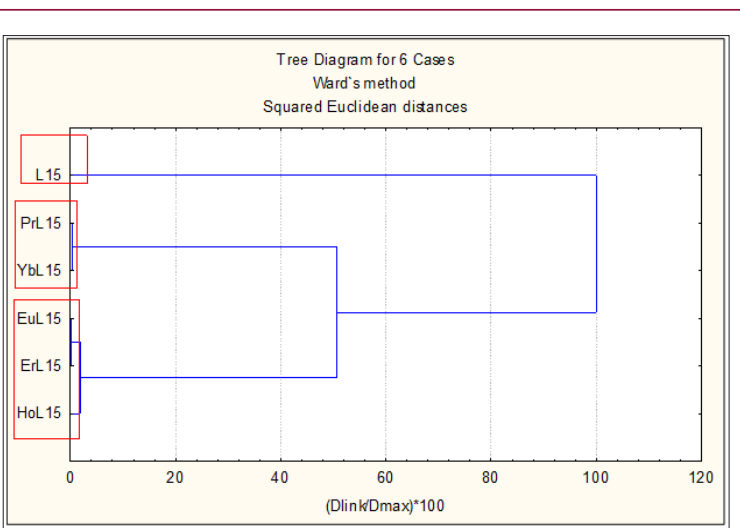

Figure 2: Hierarchical dendrogram of clustering of the ligand L15 and its complexes with $\operatorname{Pr}(\mathrm{III}), \mathrm{Yb}(\mathrm{III}), \mathrm{Eu}(\mathrm{III}), \mathrm{Er}(\mathrm{III})$, and $\mathrm{Ho}(\mathrm{III})$, based on their cytotoxicity.

\section{Cytotoxicity Data Set}

In this case the cytotoxicity of the ligand L15 and its complex compounds with $\mathrm{Pr}, \mathrm{Eu}, \mathrm{Ho}, \mathrm{Er}$ and $\mathrm{Yb}$ was studied. The same statistical approach was applied to the input data set. The hierarchical dendrogram of clustering of the chemical compounds based on their cytotoxicity is shown on (Figure 2). Two distinctive groups are formed and one outlier i.e. L15 - outlier; K1: (PrL15, YbL15); K2: (EuL15, ErL15, HoL15). Ligand L15 indicates relatively 
lowest inhibition of the cell growth (highest IC50 values for two of the cell lines but it is not the case for cell line SKW-3, where the lowest inhibition is shown by the complex compounds PrL15 and YbL15). The two objects PrL15 and YbL15 reveal their specificity by forming a separate pattern K1 marked as lowest inhibition for cell line SKW-3. The rest of the complex compounds are clustered in K2 since they represent the specificity pattern of highest inhibition power. The correlation analysis has shown that lines BV-173 and K-562 are very similar ( $\mathrm{r}=98)$ towards all compounds including the free ligand but both lines differ substantially from line SKW-3 (correlation coefficients -0.24 and -0.09 , respectively).

\section{Conclusion}

The cluster analysis applied to the bioactivity of complexes and ligands is in good agreement with the experimental data. The activity of the complexes towards all types of tested bacteria and cell lines is significantly higher than that of the ligands. The nature of the interaction of the compounds and their decomposition products with the cells must be determined to obtain a complete pharmacological characterization of the compounds. Investigations should elucidate the eventual capability of the compounds as pharmacological agents.

\section{References}

1. Sherma J (2011) High performance liquid chromatography in Phytochemical Analysis. Chromatographic Science Series 102: 513-534.

2. Cooke D (1999) Studies on the Mode of Action of Coumarins (Coumarin,6hydroxycoumarin, 7-hydroxycoumarin and Esculetin) at a Cellular Level. Dublin City University, Dublin, Ireland.

3. Murray JM, Brown SA (1982) The Natural Coumarins, Occurrence, Chemistry and Biochemistry. John Wiley\&Sons, Chichester.

4. Potdar MK, Swapnil SM, Manikrao MS (2001) Coumarin syntheses via Pechmann condensation in Lewis acidic chloroaluminate ionic liquid. Tetrahedron Letters 42: 9285-9287.

5. Song A, Xiaobing W, Kit SL (2003) A convenient synthesis of coumarin3 -carboxylic acids via Knoevenagel condensation of Meldrum's acid with ortho-hydroxyaryl aldehydes or ketones. Tetrahedron Letters 44(9): $1755-1758$.

6. Stanchev S, Anita P, Pascal R, Georgi A, Ilia M (2008) Crystal Structure of 3-Acetyl-6-methoxy-2H-1-benzopyran-2-one. Analytical Sciences 24: 183-184.

7. Kancheva VD, Boranova PV, Nechev JT, Manolov II (2010) Structureactivity relationships of new 4-hydroxy bis-coumarins as radical scavengers and chain-breaking antioxidants. Biochimie 92(9): 11381146.

8. Hamdi N, Carmen MP, Pedro V (2008) Synthesis, structure, antimicrobial and antioxidant investigations of dicoumarol and related compounds. Eur J Med Chem 43(11): 2541-2548.

9. Sardari S, Mori Y, Horita K, Micetich RG, Nishibe S, et al. (1999) Synthesis and Antifungal Activity of Coumarins and Angular Furanocoumarins. Bioorganic \& Medicinal Chemistry 7(9): 1933-1940.

10. Zavrsnik D, Muratović S, Spirtović S, Softić D, Medić Sarić M (2008) The synthesis and antimicrobial activity of some 4-hydroxycoumarin derivates. Bosnian Journal of Basic Medical Sciences 8(3): 277-281.

11. Musa M A, Badisa VL, Latinwo LM, Cooperwood J, Sinclair A, et al. (2011) Cytotoxic activity of new acetoxycoumarin derivates in cancer cell lines. Anticancer Research 31(6): 2017-2022.
12. Jung J, Lee JH, Oh S, Lee JG, Park OS (2004) Synthesis and antitumor activity of 4-hydroxycoumarin derivates. Bioorganic \& Medicinal Chemistry Letters 14(22): 5527-5531.

13. Lacy A, O Kennedy R (2004) Studies on Coumarins and Coumarin-Related Compounds to Determine Their Therapeutic Role in the Treatment of Cancer. Current Pharmaceutical Design 10(30): 3797-3811.

14. Huang L, Yuan X, Yu D, Lee KH, Chen CH (2005) Mechanism of action and resistant profile of anti-HIV-1 coumarin derivates. Virology 332(2): 623-628.

15. Xue H, Xiaofan Lu, Purong Zheng, Li Liu, Chunyan Han J, et al. (2010) Highly Suppressing Wild-Type HIV-1 and Y181C Mutant HIV-1 Strains by 10-Chloromethyl-11-dimethyl-12-oxo-calanolide A with Druggable Profile. J Med Chem 53(3): 1397-1401.

16.Jung J, Oee Sook Park (2009) Synthetic Approaches and Biological Activities of 4-Hydroxycoumarin Derivates. Molecules 14: 4790-4803.

17. Manolov I, ND Danchev (1995) Synthesis, toxicological and pharmacological assessment of some 4-hydroxycoumarin derivates. Eur J Med Chem 30(6): 531-535.

18. Chih Chia Chiang (2008) Synthesis and antimicrobial evaluation of coumarin derivates. Journal of C.C.I.T (Creative Communication and Innovative Technology) 37(1): 15-21.

19. Basile A, Sorbo S, Spadaro V, Bruno M, Maggio A, et al. (2009) Antimicrobial and Antioxidant Activities of Coumarins from the Roots of Ferulago campestris (Apiaceae). Molecules 14(3): 939-952.

20.Zavrsnik D, Selma SH, Dzenita S (2011) Synthesis, structure and antibacterial activity of 3- substituted derivates of 4-hydroxycoumarin. Periodicum Biologorum 113(1): 93-97.

21. Creaven BS, Denise A Egan, Kevin Kavanagh, Malachy McCann, Andy Noble (2006) Synthesis, characterization and antimicrobial activity of a series of substituted coumarin-3-carboxylatosilver(I) complexes. Inorg Chim Acta 359(12): 3976-3984.

22. Karaliota A, Kretsi O, Tzougraki C (2001) Synthesis and characterization of a binuclear coumarin-3-carboxylate copper (II) complexes. Journal of Inorganic Biochemistry 84(1-2): 33-37.

23. Thati A, Noble A, Creaven BS, Walsh M, McCann M, et al. (2009) Role of cell cycle events and apoptosis in mediating the anti-cancer activity of a silver(I)complex of 4-hydroxy-3-nitro-coumarin-bis(phenanthroline) in human malignant cancer cells. Eur J Pharmacol 602(2-3): 203-214.

24. Kostova I, Ilia Manolov, Irina Nicolova, Spiro Konstantinov, Margarita Karaivanova (2001) New lanthanide complexes of 4-methyl-7hydroxycoumarin and their pharmacological activity. Eur J Med Chem 36(4): 339-347.

25. Kostova I, Tsvetanka Stefanova (2010) Cytotoxicity of new Ho (III) and Pr(III) complexes. JRE 28(1): 40-46.

26.Zavrsnik A, Muratović S, Makuc D, Plavec J, Cetina M, et al. (2011) Benzylidene-bis-(4-hydroxycoumarin) and benzopyranocoumarin derivates: Synthesis, ${ }^{1} \mathrm{H} /{ }^{13} \mathrm{C}$ - NMR conformational and X-ray crystal structure studies and In Vitro antiviral evaluations. Molecules 16(7): 6023-6040.

27. Kostova I, Manolov I, Momekov G, Tzanova T, Konstantinov S, et al. (2005) Cytotoxic activity of new cerium (III) complexes of bis-coumarins. Eur J Medicinal Chem 40(12): 1246-1254.

28. Kostova I, Natasha Trendafilova, Georgi Momekov (2005) Theoretical and spectroscopic evidence for coordination ability of 3,3'-benzylidenedi4-hydroxycoumarin. New neodymium (III) complex and its cytotoxic effect. Journal of Inorganic Biochemistry 99(2): 477-488.

29. Manolov I, Caecilia MM, Nicolay D (2006) Synthesis, structure, toxicological and pharmacological investigations of 4-hydroxycoumarin derivates. Eur J Medicinal Chem 41(7): 882-890. 
30. World Organization for Animal Health (2012) OIE, Terrestrial Manual, Laboratory methodologies for bacterial antimicrobial susceptibility testing, Guideline 2.1: 1-11.

31. Clinical Lab (2009) Standards Institute (CLSI), Methods for dilution antimicrobial susceptibility test for bacteria that grow aerobically; Approved Standard, M08-A8, 29(2).

32. Valgas C (2007) Screening methods to determine antibacterial activity of natural products. Brazilian Journal of Microbiology 38: 369-380.

ISSN: 2574-1241

DOI: 10.26717/BJSTR.2018.09.001843

M Milanova. Biomed J Sci \& Tech Res

(C) This work is licensed under Creative

Submission Link: https://biomedres.us/submit-manuscript.php
33. Kahlmeter G, Brown DF, Goldstein FW, MacGowan AP, Mouton JW, et al. (2003) European harmonization of MIC breakpoints for antimicrobial susceptibility testing of bacteria. Journal of Antimicrobial Chemotherapy 52(2): 145-148.

34. Mosmann T (1983) Rapid colorimetric assay for cellular growth and survival: application to proliferation and cytotoxicity assays. J Immunol Meth 65(1-2): 55-63.

$\begin{array}{ll}\text { BIOMEDICAL } & \text { Assets of Publishing with us } \\ \text { RESEARCHES } & \text { - Global archiving of articles } \\ \text { - Immediate, unrestricted online access } \\ \text { https://biomedres.us/ }\end{array}$

